\title{
Nefarious Presentism
}

Jonathan Tallant and David Ingram

Presentists, who believe that only present objects exist, face a problem concerning truths about the past. Presentists should (but cannot) locate truth-makers for truths about the past. What can presentists say in response? We identify two rival factions: 'upstanding' and 'nefarious' presentists. Upstanding presentists aim to meet the challenge, positing presently existing truth-makers for truths about the past; nefarious presentists aim to shirk their responsibilities, using the language of truth-maker theory but without paying any ontological price. We argue that presentists should be nefarious presentists.

Keywords: presentism; truth-making; the truth-maker objection to presentism.

1. It is a period of civil war (for presentists)

Presentists, who believe that only present objects exist, ${ }^{1}$ face a familiar problem concerning truths about the past. ${ }^{2}$ It seems presentists believe each of the following: (i) presentism; (ii) truth-maker theory (truths about the past are 'made true' by some element of our ontology); and, (iii) there are (evidence-transcendent and objective) truths about the past. ${ }^{3}$ For obvious reasons, presentists will not be inclined to give up on presentism. The claim that truths about the past are 'made true' by some element of our ontology is popular and well-defended. ${ }^{4}$ And, so long as they wish to avoid flying in the face of common sense, presentists must agree that there are truths about the past, e.g. that Caesar crossed the Rubicon. (We metaphysicians defer to historians on this matter.) Hence, $<$ Caesar crossed the Rubicon $>$ is true, ${ }^{5}$ and so must have a truth-maker. But note: Caesar is not a present object. And so, it seems, there is a tension. Presentists should—but cannot—locate truth-makers for true propositions about the past.

1 Precise formulations differ. See, for instance, Crisp (2004; 2005) and Tallant (2014).

2 In fact, presentists face many problems; we're concerned here with only one.

3 We borrow this trio of theses from Cameron (2011) and his presentation of the issue.

4 Armstrong (2004) may be the canonical presentation and defence of this thesis, but many others are invested in the project. See, inter alia, Cameron (2008), Jago (2012), Lowe (2006: 177-91), and Rodriguez-Pereyra (2005).

5 We follow the convention that ' $\langle p\rangle$ ' denotes 'the proposition that $p$ '. 
What can presentists say? As it turns out, they can say many things. Indeed, there are two rival factions in the presentist camp. In the first faction are those who fight fair. These fine, upstanding presentists look to provide truth-makers for truths about the past. Such presentists aim to meet the challenge head-on and provide the ontological ground required to 'make true' the relevant propositions about the past.

By contrast, the second faction is a villainous crew. These nefarious presentists—at least one of whom even goes so far as to self-describe as a 'cheat' (Tallant, 2009; 2010)—look to use the language of truth-maker theory, without paying any price in the coin of ontology. They say things like: " $<$ Caesar crossed the Rubicon> is made true by the fact that Caesar did cross the Rubicon.” But when pressed to tell us what 'Caesar did cross the Rubicon' consists in, they demur. "Do not talk of existing truth-makers," they tell us. "Rather," they say, "<Caesar crossed the Rubicon $>$ is true because Caesar crossed the Rubicon. This is a tensed truth about the world, and there is no explanation for its truth to be given in terms of ontology." In perfectly general terms, all that nefarious presentists think we can say is that $<$ It was the case that $p>$ is true, because it was the case that $p$ (cf. Tallant, 2009: 424).

Upstanding presentists are legion—we will discuss some of their number in a moment. But, although still only a minority, we think the nefarious presentists are on the march. Each of Baia (2012), Sanson \& Caplan (2010), and Tallant $(2009,2010)$ defend views according to which no truth-makers are required for truths about the past. To our shame, we fear we must join the march. Presentists should, we think, be nefarious presentists; explaining why is the focus of this paper. But before we begin this attempted programme of conversion, it would be for the best if we could say something more about what we think should be believed. What is nefarious presentism?

We do not intend the following as an analysis, but we advise presentists to be nefarious and to endorse both of the following two principles:

(1) Truths about the past are expressed using primitive (and unanalysable) tense operators; 
(2) The primitive (and unanalysable) tense operators do not pick out some distinctive ontological category, or aspect of reality.

To clarify: nefarious cheats (like Tallant) will say " $<$ It was the case that $p>$ is true, because it was the case that p." Here, the 'was' is primitive and unanalysable. Notice, also, that Tallant will agree that this 'was' does not help us to pick out any ontology; it does not help us to speak of any distinctive metaphysical category or kind.

In contrast: Kierland \& Monton (2007) will agree with (1). They also treat tense as primitive and unanalysable by tenseless notions. But they cannot endorse (2). For Kierland \& Monton, the past-the 'brute past' - is an aspect of reality. In terms we borrow from Sanson \& Caplan's description of the view (2010: 31), this 'aspect of reality' is like an extra entity, treated much like an abstract object. It is certainly a distinctive metaphysical category (Kierland and Monton, 2007: 491). And this aspect of reality can be used to ground truths about the past. For this reason, Kierland \& Monton are not nefarious. In our terms, they are upstanding. We applaud them for their virtue but decry their metaphysic. ${ }^{6}$

Our starting point is a putative solution to the truth-maker problem proposed by Cameron $(2011 ; 2013)$, an upstanding presentist. A problem was raised for Cameron's view by Tallant \& Ingram (2012a).7 We think the problem casts light upon a dark secret, lurking at the core of upstanding presentism. This secret will be exploited to demonstrate that all presentists should turn themselves over to the nefarious side. ${ }^{8}$

\section{A problem facing a new hope}

\footnotetext{
6 Similarly, we do not think Baron's (forthcoming) view that the present is fundamental and the past is derivative is nefarious. Although Baron endorses (1), since truths about the past are expressed using primitive tense operators, Baron does not endorse (2), and treats the past as a distinctive metaphysical kind. For Baron, the past is derivative and depends for its existence upon the present. Thus, again, we do not treat Baron as kin in this debate.

7 In fact, they raise two problems. See Tallant \& Ingram (2012b) for the second.

8 We concede that some may take the arguments that follow to motivate a rejection of presentism. So be it. We say nothing (here) about why the presentist should not take this step.
} 
Cameron $(2011 ; 2013)$ defends a novel solution to the truth-maker problem for presentism. Cameron claims that what makes true the relevant propositions about the past is that objects presently instantiate what he calls 'temporal distributional properties'. The notion of a temporal distributional property is central and so requires a little unpacking.

Let us start with the notion of a spatial distributional property, as explained by Parsons (2004). Consider a domino. Its surface is mostly black with white spots. (We might say it's 'polka-dotted'.) A natural way to analyse this is via the domino instantiating different colour properties at different locations across its surface. Another way to analyse this fact is via the domino instantiating one distributional property, e.g. being-polka-dotted. The property described is spatial in that it distributes across regions of space. It is in virtue of instantiating this property that the domino has the appearance it does.

In contrast, Cameron offers temporal distributional properties. Borrowing from Tallant \& Ingram (2012a), call these 'TDPs'. An example of a TDP is: being-a-boy-then-being-a-man-then-being-an-old-man. In addition to TDPs, Cameron argues every object also instantiates a property of age. The age property is intended to pick out how far we are along the TDP (loosely speaking) ${ }^{9}$ So, crudely, if Ross instantiates the example TDP and the age property being-1, then he would presently be a boy; if Ross instantiates the TDP and being-2, then he would presently be a man; and so on.

To see how TDPs solve the truth-maker problem, consider the following (vastly simplified) example. Suppose that Ross is now a man and was a boy. $<$ Ross was a boy $>$ is true, but what makes it true? On Cameron's (2011) metaphysic, Ross instantiates the TDP, being-a-boy-then-being-a-man-then-being-an-old-man, and the age property, being-2. Notice that between them the TDP and age property fix how Ross is now,

9 We assume that exemplifying being-1 indicates the first portion of the TDP is present ('being-a-boy'), being-2 indicates the second portion of the TDP is present ('being-a-man'), and so on. 
but also how Ross was. Namely: a boy. Hence, the union of the TDP and the age property serve to make true $<$ Ross was a boy $>$, and so we have a solution to the truth-maker problem. ${ }^{10}$

In response to this new hope for presentists, Tallant \& Ingram (2012a) point to a problem that we shall rehearse here only very briefly. Tallant \& Ingram argue that it's possible an object instantiating a TDP change over time, such that it instantiates different TDPs at different times, and they further argue that this generates a problem for Cameron. To illustrate, consider the following natural progression of an object through time, where we allow that the underlined portions of the TDP are those that are 'now':

(A) The rose is red and then the rose is dead.

This would be naturally followed by:

(B) The rose is red and then the rose is dead.

The described progression is one in which we move from one portion of the TDP—the rose is red —being present, to the next portion— the rose is dead—being present. Tallant \& Ingram argue that another sequence is also possible. Begin as before:

(A) The rose is red and then the rose is dead.

But suppose that $(\mathrm{A})$ is followed by:

$\left(B^{*}\right)$ The rose is green (not red) and then the rose is dead.

10 Our claim that this allows Cameron to 'solve' the truth-maker problem may be too quick. The truth-maker problem is not just that we cannot locate truth-makers; suitable entities can always be posited ad hoc. The heart of the problem is that there are no plausible, independently motivated (etc.), entities to serve as truth-makers for truths about the past. To say that Cameron solves the problem is to further establish that his posits are plausible, which this paper does not motivate or consider. 
The progression from $(\mathrm{A})$ to $\left(\mathrm{B}^{*}\right)$ is one in which the property-bearer changes with respect to which TDP it instantiates. The rose instantiates two distinct TDPs. The TDP described in $\left(\mathrm{B}^{*}\right)$ has a different first portion from the TDP described in (A). This transition is undesirable-we shall speak, here, of this kind of transition as one that leads to 'getting the wrong results'. The scenario described is one in which it's true that the rose is red, but where it's never true (later than this) that the rose was red. After all, given $\left(B^{*}\right)$, what will be true is that the rose was green (cf. Tallant \& Ingram, 2012a: 308-9—we lean very heavily on their presentation of the problem).

Cameron (2013) looks to strike back. He makes two points. First, Cameron urges that this kind of problem infects any version of presentism that meets the truth-maker problem head-on (2013: 365-6). To illustrate the general shape of Cameron's concern, notice that any view looking to solve the truth-maker problem facing presentism, which aims to do so in an upstanding manner, must posit presently existing truth-makers. Truth-makers are entities. Entities can change over time with respect to which properties they instantiate. Thus, any upstanding presentist has to deal with this concern at some point, and will have to (at least to some extent) simply insist that the described kind of change cannot occur. ${ }^{11}$

We'll return to this point in just a moment, for we think that Cameron has, here, touched upon the dark secret we wish to exploit. However, Cameron's second point is of interest to us- those more interested in our general concern for the upstanding presentist may wish to skip ahead.

\subsection{Explaining the Illusion}

Cameron argues that Tallant \& Ingram are wrong to think entities can change with respect to which TDPs they instantiate. But, rather than simply insisting that this is so, Cameron does something more subtle;

11 By 'kind of change', here, we simply mean change where which truth-makers come to be instantiated for truths about the past don't (in fact) reflect how things were. Note, too, that this need not entail the fixity of the future. See Cameron (2011: 77-91) for an extensive discussion of how to preserve the open future on his model. 
Cameron aims to explain why it is that Tallant \& Ingram think it's possible for objects to change with respect to which TDPs they instantiate, if it isn't (in fact) possible. There are well-worn moves for Cameron to exploit here. In cases we have in mind, philosophers look to exploit something like the following principle, described by Williams (2006):

'If scenario $w$ is conceivable, then either it is possible, or there is some genuinely possible world $w^{\prime}$ that is generating the illusion that $w$ is possible.' (2006: 503)

Cameron exploits this principle by appealing to hyper-time. For Cameron, TDPs are fixed and immutable. TDPs 'describe' how an object that exemplifies them is throughout time. A change in the nature of any object in time is identified with the TDP it instantiates. Thus, Cameron claims, what Tallant \& Ingram fix upon is the possibility of some kind of change, but it's not a normal change; it's a change that occurs in 'hyper-time' whereby objects change with respect to which TDPs they instantiate. But, once again, this is not mere change. This is 'byper-change'. And, since presentists—or, at least, Cameron's presentist—don't believe hyper-time and hyper-change are actual, the mere possibility of hyper-change that occurs in hypertime can be used to explain the possibility of the illusion of this kind of change (2013: 371-2).

We're sceptical of Cameron's claim that hyper-change is involved in the change that Tallant \& Ingram (2012a) describe, from: (A) the rose is red and then the rose is dead, to: $\left(B^{*}\right)$ the rose is green (not red) and then the rose is dead. We simply don't see how hyper-time is required to make plausible this change. We illustrate our thought as follows. Suppose that the actual world, @, is such that it contains a rose, R, that instantiates the property described in (A). If $R$ has a counterpart, $R^{*}$, at another world, $w$, such that $\mathrm{R}^{*}($ at $w)$ instantiates the property described in $\left(\mathrm{B}^{*}\right)$, and such that $w$ is a future counterpart of $@$, then it seems that the change described is possible. The required counterpart-theoretic description seems relatively easy to satisfy. Suppose that every object in $w$ instantiates TDPs that accurately ground truths about how the world was when@ was present, other than $R^{*}$ and its TDP. It seems that @ is relevantly similar enough to $w$ to say that this is a way that @ could go. Further, if everything else about the rose's nature and history is such that the rose at @, R, and the rose at $w, \mathrm{R}^{*}$, are in agreement, then we think that 
the roses, $R$ and $R^{*}$, are counterparts. Thus, we think that this is a way that both the actual world and the actual rose (@ and R) could evolve. But note that we have said nothing about hyper-time. All we have talked about are roses, worlds, TDPs, and counterparts.

\subsection{Introducing 'fixing'}

In any case, let's set this point aside. We'll allow Cameron, and the other upstanding presentists, that, necessarily, the way the world is at time $t$ fixes how the world will be after $t$ (at $\left.t^{+}\right)$and how it was before $t$ (at $t)$. More idiomatically: the world cannot change in such a way as to generate the 'wrong results' of the sort described by Tallant \& Ingram (2012a).

But we now want to explore, a little, the nature of this 'fixing'. Let's abstract away from Cameron's (2011; 2013) own solution to the truth-maker problem since, as noted, Cameron thinks that (in our terms) all upstanding presentists must face a version of the problem described by Tallant \& Ingram (2012a). So, we turn our attention back to Caesar. It's true that Caesar existed. Suppose we are contemporaries of Caesar. We may say that the present existence of Caesar necessitates that it will be the case that Caesar existed, and so necessitates the truth of $<$ Caesar existed $>.{ }^{12}$ This is well and good, but needs refinement.

\section{More than mere necessitation}

It's not merely the case that Caesar's existence necessitates the future truth of $<$ Caesar existed $>$. There is more to it than that. After all, the existence of any contingent existent (e.g. Queen Elizabeth's lefteyebrow, Pokémon, batteries, etc.) necessitates the future truth of $<2+2=4>$. But the relationship between Queen Elizabeth's eyebrow and the truth of $<2+2=4>$ is quite different from the way in which

12 The language of 'necessitation' should be familiar to those acquainted with truth-maker theory, where the truth-making relation is described (minimally) as a kind of 'cross-categorial necessitation' (Armstrong, 2004: 6-7). We return briefly to this point below. 
the existence of Caesar fixes that it will be the case Caesar existed (and $<$ Caesar existed $>$ will be true). ${ }^{13}$ Mere necessitation seems quite the wrong way to describe the nature of this 'fixing'.

If the relationship between Caesar's existence and the future truth of <Caesar existed $>$ isn't mere necessitation, what is it? Here, we defer to truth-maker theorists and wider observations about analogous matters and engage in a brief detour through some discussion of the truth-maker relation itself, the relevance of which will become clear in just a moment.

The default starting position for truth-maker theorists is often the claim that truth-makers must necessitate the truth of true propositions about them. The redness of the rose must necessitate the truth of $<$ the rose is red $>$. For familiar reasons, this cannot be the whole story. Suppose that we require a truth-maker for $<2+2=4>$. If we allow that the truth-maker relation is merely one of necessitation, then Queen Elizabeth's left-eyebrow would serve to make true $<2+2=4>$. This isn't right. What we want from our truth-makers is something more; some kind of grounding - an explanation of the truth of true propositions. Queen Elizabeth's left-eyebrow manages many things, but it does not offer us any explanation of how it is $<2+2=4>$ gets to be true.

Truth-maker theorists generally describe the truth-making relation in other ways. ${ }^{14}$ The most typical response is that truth-makers ground the truth of true propositions. True propositions are true in virtue of their truth-makers. ${ }^{15}$ It seems to us that upstanding presentists should say the same thing about the connection between the way the world was and which presently existing truth-makers there are. To give

13 Readers familiar with the literature on truth-making will recognise the general shape of this concern. Truth-maker theorists do not, typically, think the relationship between truth and truth-maker is merely one of necessitation. The relation of necessitation seems too loose a connection between existent and truth. In general, and as we shall propose, the relationship is held to be the hyperintensional 'in virtue of. See Schaffer (2008).

14 Others part company with truth-maker theorists and opt for some other way to describe the connection between true proposition and reality. Popular, here, are views like the supervenience thesis. We pick up on this view in $\$ 5.4$.

15 There is healthy scepticism in parts of the literature as to whether this 'in virtue of talk can be made sense of. Of course, if it can't, then there's no truth-maker problem for presentism. Thus, we're prepared to allow the truth-maker theorist their proposed hyperintensional 'in virtue of for the sake of argument. 
an example: there exists a present truth-maker for the proposition <Caesar existed $>$ in virtue of Caesar's having existed.

And so we think that upstanding presentists must say their presently existing truth-maker, $E$, for some truth about the past, exists because of the past existence of some other entity, $e$. In other terms: that $e$ existed explains why $E$ exists. In yet more terms: $E$ exists in virtue of e having existed. To give another example: the rose instantiates the TDP being-red-and-then-being-dead, in conjunction with the age property that 'picks out' 'being-dead' as present, in virtue of the fact that the rose used to instantiate being-red-and-then-being-dead, in conjunction with the age property that 'picks out' 'being-red' as present. More loosely: that the world used to include e explains why it now includes E.

We cannot hope to prove that this point will apply to all presentist solutions to the truth-maker problem (though we think that it does). What we will do, instead, is consider some of the main contenders in the upstanding presentist camp and (briefly) demonstrate that they are suitably afflicted. In particular, we focus our attention on three quite different solutions: Bigelow's (1996) 'Lucretianism', McKinnon \& Bigelow's (2012) account of tensed instantiation ties, and Crisp's (2007) 'ersatz presentism'. In what follows, we briefly consider each in turn, in the context of how each aims to provide present truth-makers for $<$ Caesar existed $>$.

First, Bigelow (1996) claims that $<$ Caesar existed $>$ is made true by the world presently instantiating a primitive past-tensed property, having-contained-Caesar. (This is a 'Lucretian' property, and the general view is known as 'Lucretianism'.) Here the presently existing truth-maker is the world now instantiating a Lucretian property. The world now instantiates this Lucretian property in virtue of the fact that the world once contained Caesar; it is because the world was that way that the world now instantiates that property.

Second, McKinnon \& Bigelow (2012) claim that $<$ Caesar existed $>$ is made true by the world instantiating a property (e.g. containing-Caesar) in a primitive past-tensed way. This is distinct from Lucretianism; the property itself is unremarkable, but the instantiation tie is tensed. McKinnon \& Bigelow urge that there's a 
plausible relation of past-tensed instantiation that obtains presently, in addition to the typical (present-tensed) instantiation tie that also obtains presently. Here the presently existing truth-maker is the world, now, past-tensed-instantiating containing-Caesar. The world now stands in this past-tensed instantiation relation to the property containing-Caesar, in virtue of the fact that the world once contained Caesar; it is because the world was that way that the world now stands in the relevant past-tensed instantiation relation to the property in question.

Third, and finally, Crisp (2007) claims that <Caesar existed $>$ is made true by an abstract time that represents how things were when Caesar existed. (This is an 'ersatz' time, and the general view is known as 'ersatz presentism'.) Here the presently existing truth-maker is an abstract entity that represents how things were at some past time. ${ }^{16}$ Finally: the abstract entity has the very nature that it does in virtue of how things were when Caesar existed; it is because the world was that way that the relevant abstract objects exist.

So, we think, it seems each of the main upstanding presentist positions are committed to the conclusion that presently existing truth-makers for past tensed truths exist in virtue of the way things were.

And from many points of view, this seems to us to be perfectly reasonable. If the upstanding presentist wishes to say that that their presently existing truth-makers cannot get 'the wrong results', of the sort described by Tallant \& Ingram, then it seems that they owe us an explanation as to why not. After all, objects can change with respect to which properties they instantiate. So why can the presently existing truth-makers not fail to reflect the way that things were? One (perfectly sensible) answer is to say that the presently existing truth-makers cannot get the wrong result, because the presently existing truth-makers exist in virtue of how things were.

\section{The nefarious strike back}

16 More generally, ersatz presentists think that there is an abstract four-dimensional manifold of times that represent how things were, are now, and will be. This manifold is ordered by an ersatz B-theoretic 'earlier than' relation and forms an ersatz B-series of times. See Bourne (2006), inter alia. We briefly return to ersatz presentism in $\$ 5.3$. 
The shape of our concern may now be obvious. Upstanding presentists—who seek to provide truthmakers for truths about the past-must say that present truth-makers exist in virtue of entities having existed; E exists in virtue of $\mathrm{e}$. As we've already seen, there's some agreement within the truth-making literature that the truth-maker relation itself is the in virtue of relation, as it stands between true propositions and world; that is, that we should treat the truth-maker principle as the principle that true propositions are true in virtue of how the world is. ${ }^{17}$

We have said that upstanding presentists are committed to the fact that a presently existing truth-maker, $E$, is such that it exists in virtue of how things were, $e$. That is, upstanding presentists are committed to the claim that $E$ exists in virtue of $e$. If upstanding presentists can posit this kind of connection between $E$ and $e$, then there is no obvious and in principle reason that nefarious presentists cannot posit this same kind of connection between a present truth about the past, $<\mathrm{pa}>$, and how things were, $e$.

If nefarious presentists can establish this kind of connection between $<\mathrm{pa}>$ and $e$, then, we submit, there is no reason to posit a presently existing truth-maker, E. All of the work can be done by the proposition $<\mathrm{pa}>$, e, and the connection between them. Nefarious presentists claim, as seen above, that true propositions about the past are true in virtue of how things were, i.e. $e$ having existed; this, we submit, is just the same thing upstanding presentists are required to say; that $E$ exists in virtue of $e$ having existed.

We can see no obvious reason to think it possible for a tensed 'in virtue of relation to obtain between $E$ and $e$, but not between a proposition and $e$. That is, we can see no reason to think that it is permissible to say that $E$ exists in virtue of $e$, that doesn't also apply to $<\mathrm{pa}>$ being true in virtue of $e$.

Now, of course, we assume presentists will have to say something atypical about this kind of 'in virtue of connection. The in virtue of relation is normally existence-entailing, i.e. if $x$ exists in virtue of $y$, then both $x$ and $y$ exist. Upstanding presentists will have to deny this, for they allow that $E$ exists in virtue of $e$;

17 See Lopez de Sa \& Zardini (2007: 242), Rodriguez-Pereyra (2005: 21), and Schaffer (2010: 310), inter alia. 
but since $e$ is non-present, then (given presentism) $e$ does not exist. Thus, presentists will have to offer something like the following account: E exists now because $e$ existed. Further, we think that upstanding presentists will have to allow that 'existed'—as it appears in that analysis—is a primitive past-tensed claim (for, to repeat, presentists don't think there exists any non-present objects that could be deployed to offer any putative analysis).

Thus, we claim, the upstanding presentist's commitment to $E$ is redundant. Upstanding presentists are committed to an 'in virtue of relation obtaining between $E$ and $e$; between how the world is and how the world was. But if we can posit this kind of tensed 'in virtue of' relation—between past and present—-then we can see no in principle reason against allowing this relation to hold directly between how the world is with respect to which truths about the past there are and how the world was. ${ }^{18}$ And, of course, this is simply nefarious presentism.

\section{Concerns}

We can see two broad types of argument that might be made against our line here, and although we think that neither proves successful, we consider each in turn. The first type of objection tries to argue that there is no connection between $E$ and $e$ (or, more weakly, that there is no relevant connection), and that therefore there can be no analogy with a truth about the past and $e$. The second type of objection aims to draw out a relevant dissimilarity between present truth-maker, $E$, and $e$, and a truth about the past and $e$.

\subsection{No connections}

Objection: Since $E$ exists and $e$ does not, it's quite wrong of us to try to argue that there's any kind of connection between them-modal or otherwise. If there's no such connection, then, for the same reason, there can be no similar connection between a proposition $<\mathrm{p}>$ and $e$.

18 After all, why posit the kinds of truth-maker suggested by the likes of Bigelow (et al.), described above, if one thought that the right kind of relation already obtained between past object and present truth? 
Reply: We're prepared to speak rather loosely with this talk of 'connections'. All we mean to say is that both nefarious and upstanding presentists are committed to a claim of the form ' $x$ is the case in virtue of $y$ having been the case', where 'having been' is taken to be a primitive, past-tensed claim. We would thus remind the objector that all such talk of 'connection' is to be understood in this sense.

Of course, this opens up a slightly different line of attack from our opponent. Specifically, that this sense of 'connection' is misleading. What nefarious presentists require is some explanation of why truths about the past are true. Without existing relata, there can be no sense here of an explanation having been given.

We don't see why to agree with this claim. We simply don't see that no explanation has been given. Granted, it may not be an explanation to everyone's satisfaction, but that's not the same thing. More importantly, though, is the fact that upstanding presentists really cannot object in this way. Upstanding presentists require an explanation of why the present truth-makers $(E)$ cannot get the wrong results. That explanation can, so far as we can see, only be given in terms of the fact that (suitably interpreted, as we try to above) $E$ exists in virtue of how things were $(e)$. Whether we call this a 'connection' then seems largely moot. ${ }^{19}$

\subsection{Relevant differences}

Objection: The connection between $E$ and $e$ is fundamentally different from the connection between a truth about the past and $e$. On the basis of this difference, although we can say that how the world is with respect to which present truth-makers there are is in virtue of $e$, we cannot say that how the world is with respect to which truths about the past there are is in virtue of $e$.

19 Note: our argument is not Sanson \& Caplan's (2010). Sanson \& Caplan argue that the best explanation for the truth of a past-tensed proposition is given in terms of some entity having existed, as opposed to some present truth-maker. And, since the demand for a truth-maker is the call for an explanation (of why some propositions is true), we should deny that present entities are truth-makers for truths about the past.

Our point is that, to avoid Tallant \& Ingram-style concerns, upstanding presentists must posit a modal connection between the past and present, and that this connection looks to have the same (or suitably similar) modal profile as the truth-making relation. As such, there is simply no need to posit truth-makers for truths about the past. 
We're open to this kind of line being pursued, but do not yet see how it is to be convincingly defended. For instance, we see a number of differences between the cases. Truths about the past are propositions, presumably abstract entities; $E$ is not abstract (or, at least, need not be). ${ }^{20}$ But we don't see why to think that such differences are relevant to the question of whether how things were $(e)$ can be used to explain how $E$ gets to be the way that it is, or the question of whether $e$ can be used to explain how a proposition gets to be true (or false). Absent something convincing being said about why differences between cases mean that it's acceptable to say that $\mathrm{E}$ is some way in virtue of $e$, but that it's unacceptable to say that a past-tensed proposition is some way (e.g. true) in virtue of $e$, we see nothing to concern us here.

Of course, there are similar concerns in the vicinity. We might worry that one kind of 'in virtue of is not the same as another kind of 'in virtue of and that, as such, the suggested kind of 'in virtue of' is not suited to playing the truth-making role. For instance, the nefarious upstanding presentist's iteration of the in virtue of relation is not existence entailing; that $E$ exists in virtue of $e$ does not mean that e exists. And this, one might think, gives our opponent what they require. For the norm for truth-maker theorists is to insist that truths have existing truth-makers. This norm is one that makes use of a typical iteration of the in virtue of relation-one that is existence entailing. So, the reason to think that the upstanding presentist's in virtue of relation cannot be a truth-making relation is that it isn't existence-entailing.

We concede that the relation isn't existence-entailing. We are uncertain as to how it helps our opponent. Both the typical and atypical notions of 'in virtue of are hyperintensional. Both the typical and atypical relations are explanatory. Whether the upstanding presentist likes it or not, they seem to already be committed to the atypical relation, in saying that the way that things are depends upon the way that things were. If there is such a dependence, and if we can explain E's existence (and nature) by recourse to $e$, then we cannot see why we ought not to simply extend this, and say that $\langle\mathrm{p}\rangle$ depends upon $e$. For the basic story that upstanding presentists need to tell us is that the nature of $e$ fixes the nature of $E$.

20 On some accounts, e.g. Crisp (2007), the truth-makers are abstract. But this isn't a default commitment. 
For if $e$ has the capacity to fix a nature in this way, then we cannot see any in principle reason to think $e$ might not also fix the nature of propositions. And, since 'fixing the nature of a proposition' seems to us to amount to 'determining its truth-value', we see no reason to reject the claim that true past-tensed propositions are true in virtue of $e$, i.e. how things were, the way that the world was.

\subsection{The supremacy of a 'Bourne-style' semantics?}

Some presentists offer a semantics for discourse about the past that may make trouble for us. For instance, Bourne (2006) defends a version of 'ersatz presentism': times other than the present are taken to be sets of propositions. Bourne (2006: 56-57) sets up his semantics for 'was' in a very particular fashion. For instance:

'I propose that we treat past- and future-tenses as indicating where our present's corresponding time is in relation to the others... these propositions are really about how times are ordered.' (Bourne, 2006: 57)

Thus, as Bourne has it, propositions about the past are, in fact, about sets of propositions and how they are ordered. This has the result that 'presently existing truth-makers for past tensed truths exist in virtue of the way that things were' comes out as trivial. The way things were is the way the ersatz times say they are, because that's what such a semantics says 'the way things were' means: propositions about the past are about sets of propositions and how they are ordered. ${ }^{21}$

This threatens to make trouble for us. The collapse of upstanding presentism into nefarious presentism requires that the presentist is able to refer to 'the way things were' without just redirecting us to the truthmakers provided. Bourne's semantics (or, if we accept Lucretianism, a modified 'Bourne-style' semantics)

21 We don't go into detail on the nature of the semantics. Our concern isn't with Bourne's specific version of the semantics for tensed sentences, but with the general claim that such a semantics might be made to deliver the result that talk of 'the way things were' doesn't simply redirect us to the truth-makers specified by the upstanding presentist. 
simply won't permit this move: truths about the past are, in fact, about abstract or Lucretian truth-makerscall these 'surrogate grounds' in what follows. Through hooking up our semantics to these surrogate grounds, all of our problems are apparently solved.

We don't think that the upstanding presentist can make this move. Like others (e.g. Baron (2013), Merricks (2007: 133, 137), Sanson and Caplan (2010)), we think talk about the past, including past-tensed sentences, should be understood as about the past. A Bourne-style semantics denies us that; talk about the past winds-up being about surrogate grounds. A Bourne-style semantics should therefore be rejected.

Of course (and as Baron (2013: 555) notes), there may be defensive manoeuvres available to (what we call) upstanding presentists. The upstanding presentist may deny the requirement that every truth be made true by what it is about. They may say something like: every true proposition is either made true by what it is about, or else is made true by something that's suitably connected to what it is about. What upstanding presentists would have to do, then, is to insist that every truth about the past is about the past in virtue of being suitably connected to what was the case.

But we worry: a proponent of a Bourne-style semantics cannot satisfactorily express this manoeuvre. As we've explained, the Bourne-style semantics is one that treats talk about what was the case as being about surrogate grounds. Thus, the requirement that 'there having been dinosaurs is suitably connected to surrogate grounds', given the semantics in question, turns out to mean 'there being surrogate grounds is suitably connected to there being surrogate grounds'. That's trivially true, of course, but the semantics is preventing us from properly stating the very manoeuvre that's supposed to be helping us respond to the concerns of aboutness. We simply cannot talk about the past beyond the surrogate grounds. A Bourne-style semantics simply makes such talk about the surrogate grounds themselves. This, it seems, is deeply unsatisfactory.

Indeed, it seems to us that it leaves upstanding presentists facing a further difficulty. We submit (and we aren't alone in thinking so) that what we here call 'surrogate grounds' should exist because something other 
than the surrogate grounds existed. ${ }^{22}$ It's because the past was thus-and-so that these surrogate grounds exist now. With the semantics in question, we cannot make such a claim. For that the world was thus-and-so is just taken to mean that surrogate grounds exist. And that surrogate grounds exist is far from a satisfactory explanation of why surrogate grounds exist.

\subsection{The wrong connection between truth and world}

As things stand, the reader may be of the view that we should be accused of foul play. Perhaps upstanding presentists need not opt for something as ontologically inflationary as 'truth-making'. There are other accounts of the truth-making relation that treat it as a relation of explanation and that are less inflationary. ${ }^{23}$ Indeed, there are other accounts of truth itself that don't require the existence of individual (minimal) truth-makers for every proposition; they merely require that any difference in truth is accompanied by a difference in ontology. ${ }^{24}$ In making our case, we did not give upstanding presentists these options. Even though we claim to be nefarious, there are some rules of the game by which even we must abide.

We agree that there are such rules. We promise to abide by them and we think that we've behaved appropriately. What we've shown is that, on the model adopted by upstanding presentists, there's a species of 'in virtue of relation obtaining between past objects and the presently existing truth-makers that upstanding presentists posit for truths about the past.

Keep that in mind. Suppose, then, that one merely adopts a supervenience thesis of truth: no change in what's true without a change in what exists. The only existing subvenient base for truths about the past that upstanding presentists can deliver is a presently existing base (or an abstract base-that may, we suppose, be 'timeless'); they certainly cannot posit past entities to do the work. That present subvenient base must deliver the right results for truths about the past. That is, the present base (or the abstract base) must have

\footnotetext{
22 See Sanson and Caplan (2010), inter alia.

23 See, for instance, McFetridge (1990) and Liggins (2005).

24 See, for instance, Bigelow (1988).
} 
the nature that it does in virtue of the way the world was. But, we submit, 'in virtue of' is a stronger modal relation than mere supervenience; it's more demanding. As Rodriguez-Pereyra (2005: 18-19) explains: to say that 'P holds in virtue of $\mathrm{Q}$,' is to commit to something stronger than that $\mathrm{P}$ supervenes upon $\mathrm{Q}$; but that $P$ supervenes upon $Q$ follows from this stronger claim. Thus, if a true proposition supervenes upon a presently existing or abstract base, and that base exists in virtue of the way that things were, then the base also supervenes upon the way that things were. And if the base can supervene upon the way that things were, then we see no reason to think that present truth might not itself supervene upon the way that things were. The present subvenient base (once again) appears redundant.

We think that the general moral of the story is simple: to fix the (presently existing) ontological ground for a truth about the past, we must have 'the right grounds'. Those 'right grounds' can, we think, only be secured if one posits an 'in virtue of relation between the way that the world was and the presently existing grounds. Such a relation is explanatory and hyperintensional; crucially, it's stronger than other kinds of modal relation, including necessitation and supervenience. If it can obtain, then we think any modal connection can obtain between the past and the present truths, and in that case we have no reason to think that we need presently existents in order to ground truths about the past. ${ }^{25}$

\section{Concluding remarks}

Upstanding presentists try to locate presently existing truth-makers for truths about the past. Nefarious presentists do not. Nefarious presentists argue that truths about the past are true because of how things were, where no analysis of this primitive, past-tensed claim is given. We think that considerations described here militate against upstanding presentists; upstanding presentists must say that which truthmakers exist (for truths about the past) because of how things were. If both presentist camps are committed to this talk of things being how they are now because of how they were, then we do not see the

25 Things don't improve if we treat the truth-maker relation as a relation of explanation. Suppose we posit some present entity, $E$, as the explanation of why a past-tensed proposition, $<\mathrm{pa}>$ is true. The existence of $E$ will be explained by recourse to some past event or state of affairs. If explanations can span times in these ways, then we see no reason not to simply say that $<\mathrm{pa}>$ 's truth is explained by recourse to some past event or state. 
value in positing additional ontology—additional truth-makers—-to make true propositions about the past. We therefore think that presentists should be nefarious presentists.

We concede this may persuade some to abandon presentism; those tempted by truth-making may, as we have said, simply see this as a reductio of presentism. But our goal here was neither to defend nor motivate presentism. Our concern was to show that presentists should be nefarious presentists if they are to be presentists at all. Twilight is upon the upstanding presentists; soon they must fall. ${ }^{26}$

26 We are grateful to two anonymous referees for comments on a previous draft. 


\section{References}

Armstrong, D. (2004) Truth and Truthmakers. Cambridge: Cambridge University Press.

Baia, A. (2012) 'Presentism and the grounding of truth', Philosophical Studies, 159: 341-56.

Baron, S. (2013) 'Talking about the past', Erkenntnis, 78: 547-60.

Baron, S. (forthcoming) The priority of the now', Pacific Philosophical Quarterly.

Bourne, C. (2006) A Future for Presentism. Oxford: Oxford University Press.

Bigelow, J. (1996) 'Presentism and properties', Pbilosophical Perspectives, 10: 35-52.

Cameron, R. (2008) 'How to be a truthmaker maximalist', Noûs, 42: 410-23.

(2011) 'Truthmaking for presentists', in K. Bennett and D. Zimmerman (eds.) Oxford Studies in Metaphysics, Volume 6, 55-100. Oxford: Oxford University Press.

(2013) 'Changing truthmakers: reply to Tallant and Ingram', in K. Bennett and D. Zimmerman (eds.) Oxford Studies in Metaphysics, Volume 8, 362-73. Oxford: Oxford University Press.

Crisp, T.M. (2004) 'On presentism and triviality', in D. Zimmerman (ed.) Oxford Studies in Metaphysics, Volume 1, 15-20. Oxford: Oxford University Press.

_ (2005) 'Review of L. Nathan Oaklander's The Ontology of Time' Notre Dame Pbilosophical Reviews < http://ndpr.nd.edu/news/24544/> accessed 1 December 2014.

_ (2007) 'Presentism and the grounding objection', Noûs, 41: 90-109.

Jago, M. (2012) 'The truthmaker non-maximalist's dilemma’, Mind 121: 903-18.

Kierland, B. and B. Monton (2007) 'Presentism and the objection from being-supervenience', Australasian Journal of Philosophy, 85: 485-97.

Liggins, D. (2005) 'Truthmakers and explanation', in H. Beebee and J. Dodd (eds.) Truthmakers: The Contemporary Debate, 105-15. Oxford: Oxford University Press.

López de Sa, D. \& E. Zardini (2007) 'Truthmakers, knowledge and paradox’, Analysis, 67: 242-50.

Lowe, E.J. (2006) The Four Category Ontology. Oxford: Oxford University Press.

McFetridge, I. (1990) 'Truth, correspondence, explanation and knowledge', in J. Haldane and R. Scruton (eds.) Logical Necessity and Other Essays, 29-52. London: Aristotelian Society.

McKinnon, N. \& J. Bigelow (2012) 'Presentism, and speaking of the dead', Philosophical Studies, 160: 253-63.

Merricks, T. (2007) Truth and Ontology. Oxford: Oxford University Press.

Parsons, J. (2004) 'Distributional properties', in F. Jackson and G. Priest (eds.) Lewisian Themes, 173-80. Oxford: Oxford University Press.

Rodriguez-Pereyra, G. (2005) 'Why truthmakers?', in H. Beebee and J. Dodd (eds.) Truthmakers: The Contemporary Debate, 17-32. Oxford: Oxford University Press.

Sanson, D. \& B. Caplan (2010) ‘The way things were’, Philosophy and Phenomenological Research, 81: 24-39.

Schaffer, J. (2008) 'Truth and fundamentality: On Merricks's Truth and Ontology', Philosophical Books, 49: 302-16. 
- (2010) 'The least discerning and most promiscuous truthmaker', Philosophical Quarterly, 60: 307-24.

Tallant, J. (2009) 'Ontological cheats might just prosper', Analysis, 69: 422-30.

_ (2010) 'Still cheating, still prospering', Analysis, 70: 502-6.

(2014) 'Defining existence presentism', Erkenntnis, 79: 479-501.

Tallant, J. and D. Ingram (2012a) 'Presentism and distributional properties', in K. Bennett and D. Zimmerman (eds.) Oxford Studies in Metaphysics, Volume 7, 305-14. Oxford: Oxford University Press.

(2012b) ‘Time for distribution?’, Analysis, 72: 264-70.

Williams, J.R.G. (2006) 'Illusions of gunk', Philosophical Perspectives, 20: 493-513. 